\title{
Experimental investigation of heat transfer in a falling down rivulet of liquid FC-72 on the vertical heated foil
}

\author{
Tatyana Ponomarenko* \\ Novosibirsk State Technical University, 630073, K. Marx Ave., 20, Novosibirsk, Russia, \\ Kutateladze Institute of Thermophysics SB RAS, 630090, Lavrentiev ave. 1, Novosibirsk, Russia
}

\begin{abstract}
Heat transfer at rivulet FC-72 flow over the constantan vertical heated foil with the length of $80 \mathrm{~mm}$, width of $35 \mathrm{~mm}$, and thickness of 25 $\mathrm{mm}$ was studied experimentally. Distributions of temperature on the bottom side of foil from the rivulet flow using the infrared thermographic data were obtained. In the future heat flux from the foil will be calculated with help of Koshi problem solution. It was shown that the rivulet width as the liquid flow rate increases, and it narrows as heat power increases due to the high evaporation rate. In the case with water, the rivulet narrows not so intensively as compared with the rivulet of FC-72 liquid. Good wettability and low heat of vaporization of FC-72 liquid contribute to using it to develop effective cooling systems.
\end{abstract}

\section{Introduction}

The well-known regularity, which was observed by Gordon Moore in 1965, that the number of transistors in microprocessors almost doubles each two years, as their new models are introduced is still relevant. Due to the growth of transistor counts of modern computer microprocessors, many parameters, including such a major one as throughput, improve, but the heat output that should be dissipated from the processing unit also increases. Moreover, an increase in the temperature by $10^{\circ} \mathrm{C}$ shortens the lifespan of the processor by half. Therefore, creating an effective cooling system is one of the major objectives for today. The main cause for cooling is an unstable operation, and eventually the breakdown of the process as the result of exceeding a certain critical temperature threshold for a certain period of time.

The liquid cooling system with the rivulet flow, which is a particular case of the liquid film flow limited by the interface from both sides - the contact line of three phases, has prospects. The high heat transfer coefficient is observed in the small field of three-phase contact line - the micro-region [1]. Therefore, the use of rivulet flows in the cooling systems is a promising practice.

Numerous studies that deal with the rivulet flows and its specific characteristics have been conducted. Many studies focused on the rivulet flow over the inclined plane and the

*Corresponding author: t.evans2010@yandex.kz 
impact of surface tension and viscosity on the emergency of varieties of rivulet flows [2]. When liquid is flowing down over the inclined flat surface, a number of various flow regimes, depending on the flow rate, the physical properties of liquid and the material of the inclined surface as well as the incline itself, can be observed. The results of such studies were used to plot the maps of varieties of rivulet flows of different liquids (water, water solution of ethyl alcohol, water solution of glycerine) over the inclined plate. As the liquid flow rate increased, the drop flow, straight flow, meandering flow, which converted into the film flow [2-4], were observed.

The LIF method (Laser Induced Fluorescence method) was used in [5] to measure the local thickness of the rivulet flows of water solutions of glycerine and ethanol that have the wave structure and flow down the inclined plate, and the maps of varieties of wave formation at the rivulet flows were plotted.

Heat transfer in an evaporating droplet on the horizontal heated foil and in a water rivulet flowing down over the vertical heated foil was studied in $[6,7]$. The fluctuating temperature measurements made by the IR-scanner were used to solve the Cauchy problem and to measure heat flux density on the surface with the droplet and on the surface with the rivulet. This showed that maximal heat flux density was observed near the contact line of an evaporating droplet, which 5-7 times higher than the average heat flux density from the entire foil surface. The experiment with a water rivulet confirmed that the heat transfer intensity in the micro-region near the contact line of wetting is higher than that in average in the rivulet in the micro-region and leads to a local temperature drop in this region.

The determination of heat flux density using the infrared thermographic data is an effective method of experimental studies of three-phase contact line. This method is used in the current study.

Therefore, the current study aims to determine heat flux density in the region of threephase contact line of the liquid rivulet flowing down over the heated surface, using the IRscanner and the method for solving the ill-conditioned problems.

Unlike the previous similar experiments [7] when water was used as the liquid, FC-72 liquid developed for cooling supercomputers was used in the current study.

Fluorinert Electronic Liquid (FC-72) is a transparent, colourless, thermally and chemically stable liquid cooling agent. It is compatible with sensitive materials, nonflammable and almost nontoxic and leaves no residue after evaporation. The heat of vaporization of the liquid is substantially lower than that of water. The unique combination of the properties makes FC-72 ideal for use in many areas of electronics, for example immersion cooling systems and film cooling systems that are under active development at present.

The value of the contact angle on the substrate of the constantan foil with black paint (graphite 33) for FC-72 - $10 \pm 0,4^{\circ}$ that was determined with the help of the gas (air) bubble method testifies to better wettability as compared with that of water $-63^{\circ}$ (Fig. 1 ).

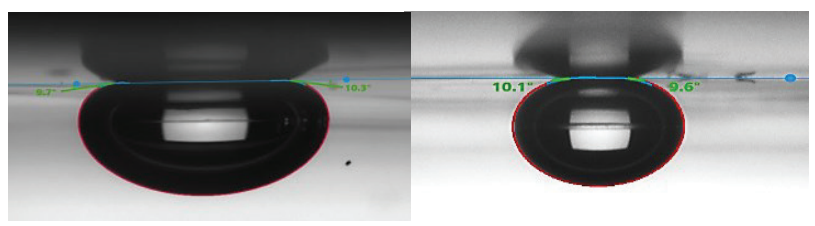

Fig.1. The determination of the value of the contact angle of the constantan foil with black paint for FC-72, using the gas (air) bubble method.

This illustrates once again that good wettability and low heat of vaporization of FC-72 liquid contribute to using it to develop effective cooling systems 


\section{Experimental setup}

The scheme of the experimental setup and the photograph of the setup in operation are presented on Fig. 2 a and b.

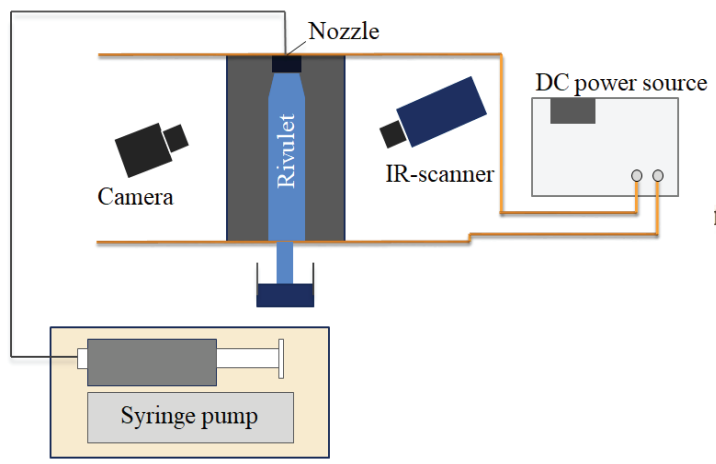

b

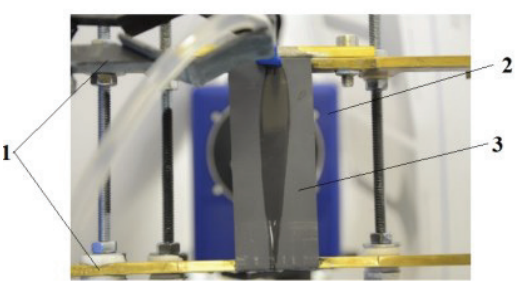

Fig.2. $\mathrm{a}$ - the scheme of the experimental setup; $\mathrm{b}$ - the photograph of the FC-72 liquid rivulet flowing down over the heated foil at $\mathrm{Q}=1 \mathrm{ml} / \mathrm{min}, \mathrm{P}=0,09 \mathrm{~W}$ : 1- brass electrodes, 2 - IR-camera, 3 foil with rivulet.

The vertical foil with the length (l) of $80 \mathrm{~mm}$, the width (w) of $35 \mathrm{~mm}$ and the thickness (h) of 25 microns was used to conduct the experiments for the current study. The material of the foil is constantan, the density is $8.9 \mathrm{~g} / \mathrm{cm} 3$, heat capacity is $0.41 \mathrm{~J} /(\mathrm{g} \cdot \mathrm{K})$ and heat conductivity is $23 \mathrm{~W} /(\mathrm{K} \cdot \mathrm{m})$. Constantan is a thermostable copper $(\mathrm{Cu})$ containing alloy (about 59\%) with the addition of nickel (Ni) (39-41\%) and manganese $(\mathrm{Mn})(1-2 \%)$. The liquid was injected with the flow rate of $0.1-5 \mathrm{~mL} / \mathrm{min}$ to the foil through the tube with a special nozzle using the Cole-Parmer EW-74905-54 syringe pump. The foil was connected to the DC power source TTi QPX 1200L through the brass electrode holders. The power source was used to heat the foil and regulate with heat power that was generated on the foil in the range of 0.09 to $1.47 \mathrm{~W}$. The Nikon D 7000 camera and the Titanium $570 \mathrm{M}$ infrared (IR) scanner were used to make the observations. The foil was coated with black graphite paint with the emissivity factor of about 1 . The ambient air temperature was $30,2-30,5^{\circ} \mathrm{C}$, humidity ranged from 35 to $40 \%$. The Testo 646 multimeter was used to measure the ambient air temperature and humidity.

\section{Experimental findings}

An IR-scanner was used to measure distributions of temperature on the bottom side of foil from the rivulet flow (Fig. 3). The experimental findings were compared with the findings of similar experiment when super-purified water obtained by the Milli-Q system was used as a liquid. It was found out experimentally that the flow regimes of two liquids differ from each other due to substantial difference in the wetting properties. 


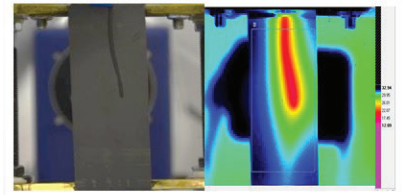

a

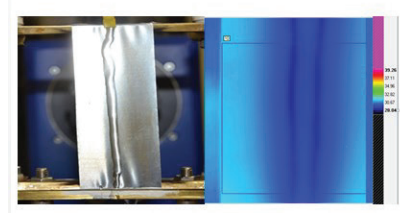

d

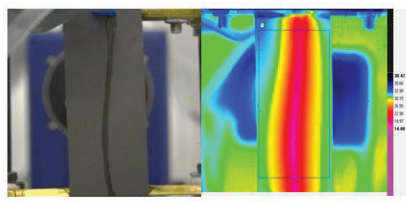

$\mathrm{b}$

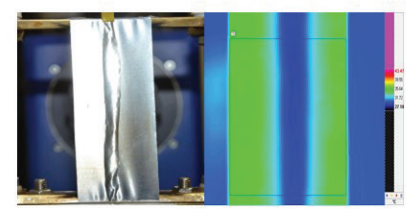

e

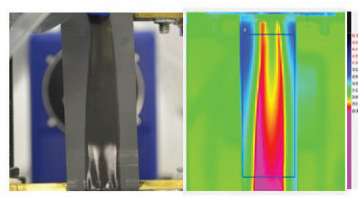

C

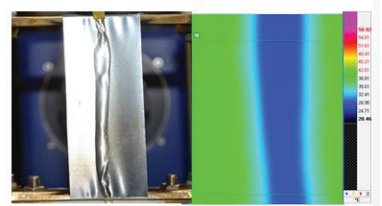

$\mathrm{f}$

Fig.3. The photographs of the rivulet flowing down over the heated foil and the thermograms from the side opposite to the rivulet. FC-72: $\mathrm{a}-\mathrm{Q}=0,1 \mathrm{ml} / \mathrm{min}, \mathrm{q}_{\mathrm{av}}=15,049 \mathrm{~W} / \mathrm{m}^{2} ; \mathrm{b}-\mathrm{Q}=1 \mathrm{ml} / \mathrm{min}, \mathrm{q}_{\mathrm{av}}=$ $97,45 \mathrm{~W} / \mathrm{m}^{2} ; \mathrm{c}-\mathrm{Q}=5 \mathrm{ml} / \mathrm{min}, \mathrm{q}_{\mathrm{av}}=237,637 \mathrm{~W} / \mathrm{m}^{2}$. Water: $\mathrm{d}-\mathrm{Q}=10 \mathrm{ml} / \mathrm{min}, \mathrm{q}_{\mathrm{av}}=16,7 \mathrm{~W} / \mathrm{m}^{2} ; \mathrm{e}-$ $\mathrm{Q}=10 \mathrm{ml} / \mathrm{min}, \mathrm{q}_{\mathrm{av}}=98,0 \mathrm{~W} / \mathrm{m}^{2} ; \mathrm{f}-\mathrm{Q}=100 \mathrm{ml} / \mathrm{min}, \mathrm{q}_{\mathrm{av}}=226,0 \mathrm{~W} / \mathrm{m}^{2}$.

The photographs were used to measure the width of the rivulet. The experimental findings were used to draw the curves illustrating the dependence of the width of the rivulet on heat power at the given rates and the dependence of the width of the rivulet on the liquid flow rate at the given heat power rates (Fig. 4 and 5).

FC-72:

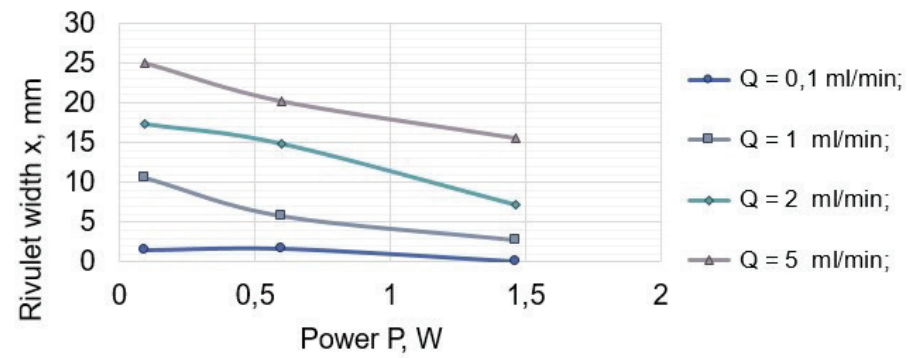

Water:

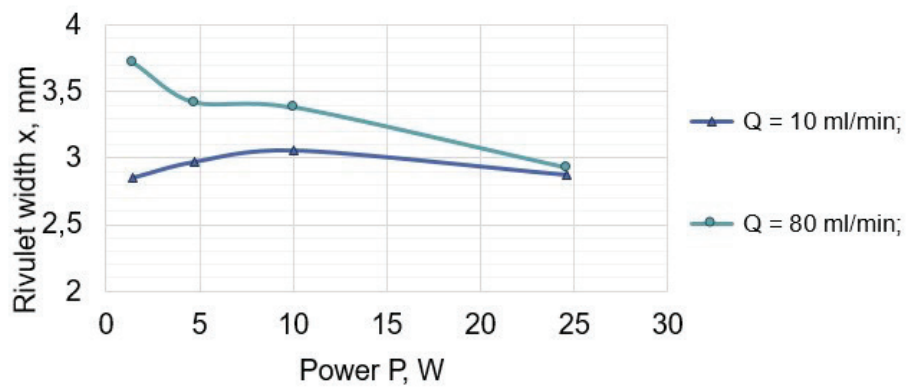

Fig.4. The curves illustrating the dependence of the width of the FC-72 rivulet and water rivulet on the power. 
FC-72:

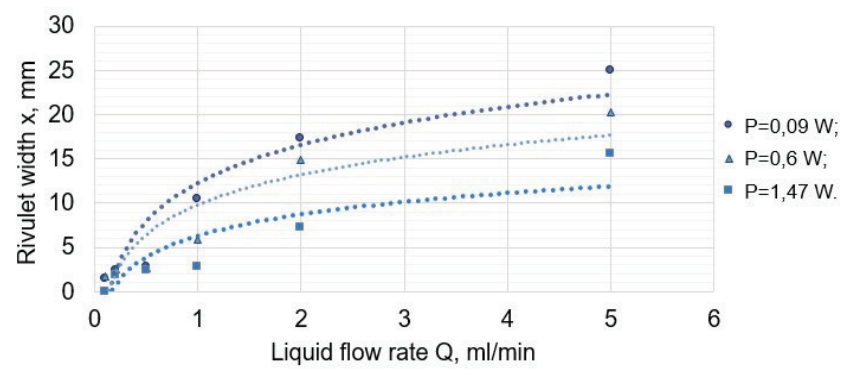

Water:

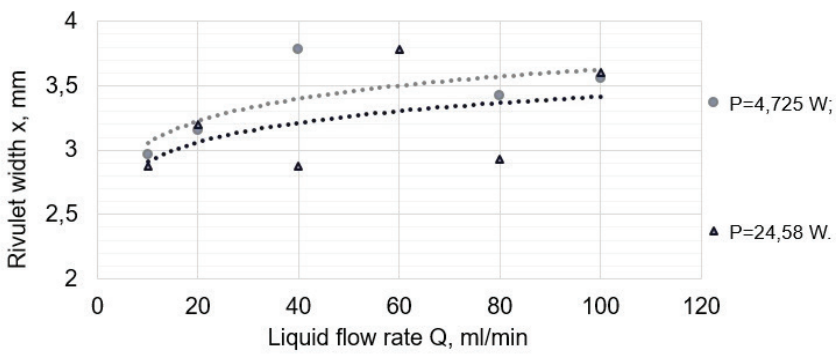

Fig.5. The curves illustrating the dependence of the width of the FC-72 rivulet and water rivulet on the liquid flow rate.

The curves show that the rivulet widens as the liquid flow rate increases, and it narrows as heat power increases due to the high evaporation rate. In the case with water, the rivulet narrows not so intensively as compared with the rivulet of FC-72 liquid.

This study was performed in the framework of the Russian Science Foundation grant (Agreement No. 14-19-01755).

\section{References}

1. Stephan P., Brandt C, Heat Transfer Engng. 25, 78-85 (2004)

2. Schmuki P., Laso M., J. Fluid Mechanics. 215, 125-143 (1990)

3. Hirt C.W, Los Alamos: Flow Sci., 7 (1998)

4. Su G.W., Geller J.T., Pruess K., Wen F., Water Resources Research. 35, 1019-1037 (1999)

5. Alekseenko S.V., Bobylev A.V., Kharlamov S.M., Markovich D.M., Proc. of 14th Int. Symp. on Applications of Laser Techniques to Fluid Mechanics, Lisbon, Portugal, 7 10 July, 8 (2008)

6. Marchuk I., Karchevsky A., Surtaev A., Kabov O., Intern. J. of Aerospace Engng. Art. ID 391036. 5 (2015)

7. Cheverda V.V., Marchuk I.V., Karchevsky A.L., Orlik E.V., Kabov O.A., Thermophysics and Aerodynamics, 23, 3 (2016) 